\section{Rapid Screening of Plasmid DNA by Direct Sequencing from Bacterial Colonies}

BioTechniques 29:436-438 (September 2000)

Procedures such as cloning into plasmid vectors and yeast two-hybrid screens require a quick method for screening large numbers of bacterial colonies. This method is required to check for DNA inserts in their correct orientation and to identify positive gene interactions before further analysis is undertaken. Various methods are available to reduce the amount of time required for plasmid DNA isolation when screening colonies $(2,4,8)$, including bypassing the DNA isolation step and sequencing bacterial colonies directly $(5,6)$. We have streamlined the sequencing of plasmid DNA directly from bacterial colonies by minimizing the amounts of reagents required and the time and effort expended. This method allows a person to cycle sequence directly from bacterial colonies using the BigDye $^{\mathrm{TM}}$ Terminator Cycle Sequencing Ready Reaction mixture (PE Biosystems, Foster City, CA, USA). The cycle sequence products are run on an automated DNA sequencer, and approximately $500 \mathrm{bp}$ of reliable plasmid DNA sequence may be obtained within one working day (See Protocol).

We obtained plasmid DNA sequences from $E$. coli DH5 $\alpha$ cells transformed with two different plasmid vectors, pcDNA3 and pACT (Figure 1). The pcDNA3 insert was sequenced using the T7 and SP6 primers. The pACT yeast vector insert was sequenced using the GAL4-activating domain primer (3). We had an overall success rate of $66 \%$ for obtaining readable plasmid DNA, and there were no observable differences in the quality of the plasmid DNA sequence obtained from either vectors or primers. Using this procedure, we confirmed the identity and orientation of the insert in the pcDNA3 vector. The success of obtaining DNA sequence directly from plasmids using this method depends on the sequencing primer and the amount of bacterial colony. It is recommended that initial sequencing trials
Protocol

1. Use micropipet tips to pick bacterial colonies from LB agar plates. Wooden toothpicks are not recommended because they may inhibit PCR (7). First, pass the autoclaved micropipet tips through a flame to seal the opening and ensure sterility and then use it to remove the entire bacterial colony. The size of the colony should be approximately $1.5 \mathrm{~mm}$ (smaller colonies do not provide enough DNA and larger colonies overload the system). The bacterial colonies do not have to be freshly grown. Fresh colonies or colonies stored up to a month at $4^{\circ} \mathrm{C}$ may be used.

2. Place the tip with the colony in a microcentrifuge tube $(0.2-\mathrm{mL}$ or $0.6-\mathrm{mL}$ tube specific to the thermal cycler) containing $3 \mu \mathrm{L}$ sequence dilution buffer (PE Biosystems). Stir the tip to resuspend the bacterial colony. The $1 \times$ PCR buffer (with $\mathrm{MgCl}_{2}$ ) may be used in place of the sequence dilution buffer, but sequences are not as good. The use of water instead of buffer also results in poor sequence qualtity. When processing a large number of samples, simply leave the micropipet tip in each PCR tube until all the bacterial colonies have been picked, then resuspend the colonies and remove the micropipet tips.

3. Streak the leftover bacteria from the micropipet tip on to a selective LB plate to maintain the colonies for future plasmid preparations.

4. Add between 8 and 20 pmol sequencing primer to each microcentrifuge tube. We used 8 pmol GAL4-activating domain primer and 20 pmol each T7 and SP6 primers. Increasing the primer concentration may help to compensate for poor sequencing primers.

5. Briefly vortex the sample and centrifuge. Heat the samples at $96^{\circ} \mathrm{C}$ for $10 \mathrm{~min}$ in the thermal cycler. A drop of mineral oil must be added before heating if using a thermal cycler without a heated lid.

6. Add $0.5 \mu \mathrm{L}$ (larger volumes result in a poor sequence) BigDye mixture directly to the colony sample immediately after heating, centrifuge and return to the thermal cycler to begin cycle sequencing. The total volume of reagents in each microcentrifuge tube should be between 5 and $8 \mu \mathrm{L}$. Removing the supernatant from the tube does not result in better sequence quality (data not shown). The cycle sequence profile varies with the type of thermal cycler.

$\begin{array}{ll}\text { PTC-100 } & \text { GM } \\ \text { thermal controller } & \text { GeneAmp } \\ \text { (MJ Research, Waltham, MA, USA) } & \text { System } 2400 \\ \text { (PE Biosystems) }\end{array}$

denature at $96^{\circ} \mathrm{C}$ for $1 \mathrm{~min}$

anneal at $50^{\circ} \mathrm{C}$ for $15 \mathrm{~s}$

extend at $60^{\circ} \mathrm{C}$ for $4 \mathrm{~min}$

repeat for 25 cycles

denature at $96^{\circ} \mathrm{C}$ for $10 \mathrm{~s}$ anneal at $40^{\circ} \mathrm{C}$ for $25 \mathrm{~s}$ extend at $60^{\circ} \mathrm{C}$ for $4 \mathrm{~min}$ repeat for 25 cycles

Annealing temperature for the GeneAmp PCR System is set at a lower temperature $\left(40^{\circ} \mathrm{C}\right)$ to provide conditions so that various primers work.

7. Following cycle sequencing, the products are precipitated and dried. When using a thermal cycler that requires mineral oil, care must be taken to remove all of the oil because this will affect the results of automated DNA sequencing. To remove the oil, simply transfer the sample to a piece of Parafilm ${ }^{\circledR} M^{\star}$. With a pipet tip, lead the bead of the sequence mixture along the Parafilm. The mineral oil will remain behind, leaving the clean cycle sequencing product. Precipitate the cycle sequence product in a final volume of $60 \%$ ethanol in a microcentrifuge (impurities of $95 \%$ ethanol may inhibit sequencing). Allow the precipitate to form for a minimum of $1 \mathrm{~h}$ at room temperature (overnight precipitations may produce a cleaner sequence signal). Centrifuge the sample at top speed for $15 \mathrm{~min}$ at room temperature and remove all of the ethanol (the pellet is usually not visible). Centrifuge again to remove any remaining ethanol that contains salts and unincorporated fluorescent ddNTPs that will affect the automated DNA sequencing. The pellet is then vacuum or air-dried.

8. Follow the manufacturer's standard protocols (1) to prepare for automated DNA sequencing by resuspending the DNA pellet in $7 \mu \mathrm{L}$ Template Suppression Reagent (TSR) and analyze on an ABI PRISM ${ }^{\mathrm{IM}} 310$ genetic analyzer (PE Biosystems). 


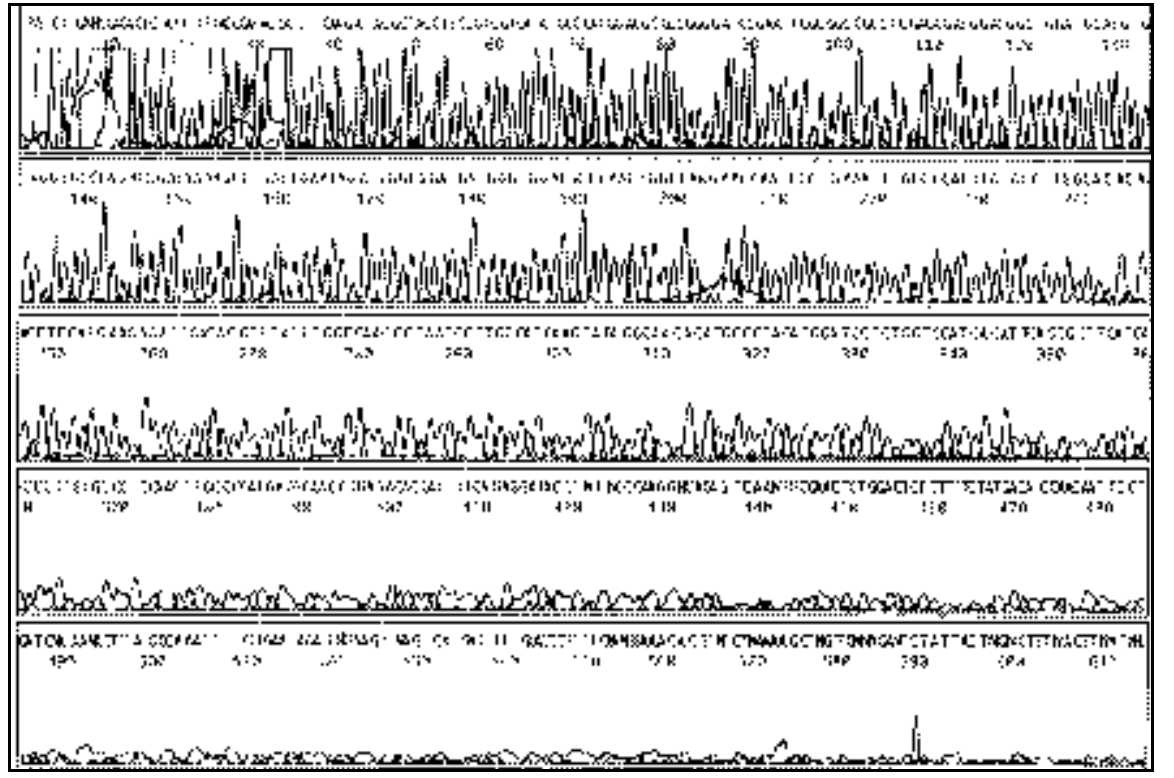

Figure 1. Electropherogram of plasmid DNA sequence obtained by direct sequencing from $E$. coli colonies. The sequence shown was obtained using the GAL4-activating domain primer for the pACT cloning vector. A BLAST search (www.ncbi.nlm.nih.gov/BLAST) identified nucleotides 23-97 as pACT vector sequence and nucleotides 111-481 as human cytochrome P450IIEI gene sequence. The sample was sequenced on an ABI PRISM 310 genetic analyzer using a $47 \mathrm{~cm} \times 50 \mu \mathrm{m}$ capillary.

should vary amounts of bacteria and primer to determine optimal conditions for sequencing. The sequencing primer and amount of bacterial colony also will determine the length of the DNA sequence obtained. Less than optimal sequencing conditions will allow determination of a shorter but adequate length of sequence (250 bp).

This protocol provides a simplified method for rapid screening of plasmid DNA when full-length DNA sequence is not required, especially to verify that DNA fragment cloning is successful and in the correct orientation, and to identify genes recovered from clone libraries (e.g., yeast two-hybrid screen). Plasmid DNA sequences may be obtained within one working day if the bacterial colonies are of adequate size. Many samples may be processed at one time because the colony preparation and cycle sequencing are performed in a single tube.

\section{REFERENCES}

1.Applied Biosystems. 1996. ABI PRISM ${ }^{\mathrm{TM}} 310$ genetic analyzer: User's Manual. PE Biosystems, Foster City, CA.

2.Chen, Q., C. Neville, A. MacKenzie and R.G. Korneluk. 1996. Automated DNA sequencing requiring no DNA template purifica- tion. BioTechniques 21:453-457.

3.Gietz, R.D., B. Triggs-Raine, A. Robbins, K.C. Graham and R.A. Woods. 1997. Identification of proteins that interact with a protein of interest: applications of the yeast two-hybrid system. Mol. Cell. Biochem. 172:67-79.

4.He, M., A. Wilde and M.A. Kaderbhai. 1990. A simple single-step procedure for small-scale preparation of Escherichia coli plasmids. Nucleic Acids Res. 18:1660.

5.Kilger, C., M. Krings, H. Poinar and S. Pååbo. 1997. "Colony sequencing": direct sequencing of plasmid DNA from bacterial colonies. BioTechniques 22:412-418.

6.Krishnan, B.R., R.W. Blakesley and D.E. Berg. 1991. Linear amplification DNA sequencing directly from single phage plaques and bacterial colonies. Nucleic Acids Res. 19:1153.

7.Lee, A.B. and T.A. Cooper. 1995. Improved direct PCR screen for bacterial colonies: wooden toothpicks inhibit PCR amplification. BioTechniques 18:225-226.

8.Tarczynski, M.C., W.J. Meyer, J.J. Min, K.A. Wood and R.J. Hellwig. 1994. Twominute miniprep method for plasmid DNA isolation. BioTechniques 16:514-519.

We thank Don Dubik, Elizabeth Henson and Ian Lewkowich from the Manitoba Institute of Cell Biology and Nathalie Bernard from PE Applied Biosystems for technical assistance and helpful discussions. This work was funded by the Manitoba Cancer Treatment and Research Foundation and the Medical Research Council of Canada. J.B.G. was supported by a George H. Sellers Endowment Fund Fellowship, and R.R. was supported by a Medical Research Council Studentship. Address correspondence to Dr. Jennifer Brown Gladden, Manitoba Institute of Cell Biology, 100 Olivia Street, Winnipeg, MB R3E 0V9, Canada. email: brownjg@cc.umanitoba.ca

Received 15 November 1999; accepted 30 May 2000.

Jennifer G. Brown Gladden ${ }^{1,2}$, Reena Ray ${ }^{1,2}$, R. Daniel Gietz ${ }^{2}$ and Michael R.A. Mowat ${ }^{1,2}$ ${ }^{1}$ Manitoba Institute of Cell Biology

${ }^{2}$ University of Manitoba Winnipeg, MB, Canada 